\title{
Effect of complementation of cattle cooling systems with feedline soakers on lactating dairy cows in a desert environment
}

\author{
X. A. Ortiz, ${ }^{\star}$ J. F. Smith, ${ }^{\star 1}$ B. J. Bradford, ${ }^{\star}$ J. P. Harner,† and A. Oddy‡ \\ *Department of Animal Sciences and Industry, and \\ †Department of Biological and Agricultural Engineering, Kansas State University, Manhattan 66502 \\ ‡NADA Al-Othman, Al Ahsa, Saudi Arabia
}

\section{ABSTRACT}

Two experiments were conducted on a commercial dairy farm in eastern Saudi Arabia to investigate the effects of Korral Kool (KK; Korral Kool Inc., Mesa, AZ) cattle cooling systems complemented with feedline soakers on core body temperature (CBT) of dairy cows. In both experiments, cows had access to KK $24 \mathrm{~h} / \mathrm{d}$. In the first experiment, 7 primiparous and 6 multiparous lactating Holstein dairy cows were assigned to 1 of 2 pens, which were assigned randomly to treatment sequence over $4 \mathrm{~d}$ in a switchback design. Soakers were on (ON24) or off (OFF24) for $24 \mathrm{~h} / \mathrm{d}$. For the second experiment, 20 multiparous lactating Holstein cows were assigned randomly to 1 of 2 pens, which were assigned randomly to treatment sequence in a switchback design. This experiment lasted $4 \mathrm{~d}$ and feedline soakers alternately remained off or were on (ON12) for $12 \mathrm{~h} / \mathrm{d}$. In experiment 1 , average ambient temperature was 30 $\pm 0.9^{\circ} \mathrm{C}$ and average relative humidity was $44 \pm 14 \%$ (mean $\pm \mathrm{SD}$ ). Feedline soakers complementing KK systems for $24 \mathrm{~h} / \mathrm{d}$ decreased the mean CBT of lactating dairy cows compared with KK systems alone (38.80 vs. $38.98 \pm 0.061^{\circ} \mathrm{C}$, respectively). A significant treatment by time interaction was found. The greatest treatment effects occurred at $2100 \mathrm{~h}$; treatment means at this time were 39.26 and $38.85 \pm 0.085^{\circ} \mathrm{C}$ for $\mathrm{OFF} 24$ and $\mathrm{ON} 24$ treatments, respectively. In experiment 2 , average ambient temperature was $35 \pm 1.5^{\circ} \mathrm{C}$ and average relative humidity was $33 \pm 16 \%$. Feedline soakers running for $12 \mathrm{~h} / \mathrm{d}$ significantly decreased the mean 24-h CBT from 39.16 to $38.99 \pm 0.084^{\circ} \mathrm{C}$. Treatment by time interaction was also significant; the greatest treatment effects occurred at $1500 \mathrm{~h}$, when ON12 reduced CBT from 39.38 to $38.81 \pm 0.088^{\circ} \mathrm{C}$. These results demonstrate that complementing the KK system with feedline soakers decreased the CBT of dairy cows housed in desert environments. However, the combined systems were not

Received February 1, 2010.

Accepted September 20, 2010.

${ }^{1}$ Corresponding author: jfsmith@ksu.edu sufficient to lower CBT to normal temperatures in this extreme environment.

Key words: heat stress, evaporative cooling, feedline soaker

\section{INTRODUCTION}

In 2003, it was estimated that heat stress causes a loss of $\$ 897$ million in the US dairy industry annually (St-Pierre et al., 2003). These losses are the result of extreme weather conditions and cows being inadequately cooled. In arid regions, which have high ambient temperatures and low humidity, it is necessary to cool cows with a cooling system to mitigate the negative effects of heat stress. Evaporative cooling is a good option to control the environment for cows.

The Korral Kool (KK; Korral Kool Inc., Mesa, AZ) system is a reverse chimney evaporative cooling system that decreases the temperature of the air surrounding dairy cows. Previous experiments have demonstrated that in arid regions, core body temperature (CBT) of primiparous and multiparous cows was higher than the mean CBT of cows in thermoneutral conditions (Ortiz et al., 2009) even when KK systems were operated continuously. These results suggested that additional mitigation measures might be required to decrease the negative effect of high ambient temperatures.

As temperature increases, the evaporation mechanism of heat flow from the cow to the environment becomes more important. It has been estimated that at $30^{\circ} \mathrm{C}$, approximately $85 \%$ of the total evaporative heat loss in lactating cows is through evaporation from the skin (Maia et al., 2005). Feedline soakers wet the cow's back and then turn off to provide enough time for the water to evaporate. Therefore, feedline soakers may be a logical complement to evaporative cooling because they increase the cow's heat exchange through evaporation. Complementing evaporative cooling with feedline soakers has been shown to decrease CBT, increase feed intake, and increase milk production in tropical climates (Brouk, 2005; Armstrong et al., 2007), but little research has been conducted to evaluate the 
combination of evaporative cooling and feedline soakers in arid climates.

\section{MATERIALS AND METHODS}

\section{Experimental Design}

Two experiments were conducted on a commercial dairy farm in eastern Saudi Arabia to investigate the effects of complementing KK systems with feedline soakers on CBT of lactating cows housed in an arid environment. Experimental procedures were approved by the Institutional Animal Care and Use Committee at Kansas State University. The first experiment was conducted during September 2007, and the second experiment was performed in August 2008. Cows were housed in desert barns; a covered area over the feeding area and part of the dry lot with an area of $10 \mathrm{~m}^{2}$ per cow provided shade. All pens had KK evaporative cooling systems located in openings on the roof. The KK units were $1.29 \mathrm{~m}$ in diameter with a 3-hp motor and were located at $6-\mathrm{m}$ intervals. The KK units were operated $24 \mathrm{~h} / \mathrm{d}$ in both experiments regardless of treatment. Weighted curtains were placed on the side of the roof to keep the cooled air inside the barn. Feedline soakers were installed on the feed line of the pens and operated with a controller (C-440S, Edstrom Industries Inc., Waterford, WI). Feedline soakers were set to run at a frequency of 5 min (36 s on and $264 \mathrm{~s}$ off). During every cycle, $1 \mathrm{~L}$ of water was sprayed over $61 \mathrm{~cm}$ of feedline.

In both experiments, CBT measurements were obtained at 5-min intervals with data loggers (Hobo U12, Onset Computer Corp., Bourne, MA) attached to blank continuous intravaginal drug release (CIDR, Pfizer Animal Health, New York, NY) devices. Data loggers were placed in cows for $5 \mathrm{~d}$ in experiment 1 and 2 .

All animals were milked 4 times per day at 0600, 1200, 1800, and 0000 h. Cows were cooled by KK systems operated continuously in the holding pen and soakers placed in the exit lane. Because of the short duration of these experiments, DMI and milk yield of the animals were not analyzed.

In experiment 1, 7 primiparous (mean milk production $=40 \pm 1.6 \mathrm{~kg} / \mathrm{d}$ and $53 \pm 2.1 \mathrm{DIM})$ and 6 multiparous (mean milk production $=47 \pm 1.8 \mathrm{~kg} / \mathrm{d}$ and $28 \pm 1.9$ DIM) Holstein dairy cows were housed in 1 of 2 pens. Each pen had $14 \mathrm{KK}$ units and 275 headlocks $(76 \mathrm{~cm})$. The stocking density in the primiparous and multiparous pens was 250 and 224 cows, respectively. Primiparous and multiparous cows were housed separately. Feedline soakers were alternately turned on (ON24) and off (OFF 24) for 24-h periods over $4 \mathrm{~d}$. Each pen received each treatment twice over the course of $4 \mathrm{~d}$. Ambient temperature and relative humidity were collected hourly from a weather station located on the farm.

In experiment 2, 20 multiparous Holstein dairy cows $(67 \pm 6.9 \mathrm{DIM}$ and $44 \pm 3.8 \mathrm{~kg} / \mathrm{d}$ of milk production $)$ were assigned to 1 of 2 pens. Each pen had $14 \mathrm{KK}$ units and 275 headlocks $(76 \mathrm{~cm})$. The stocking density of the 2 pens was 231 and 234 cows. Pens were assigned randomly to a sequence of treatments in a switchback design. Feedline soakers remained off (OFF24) in one of the pens and were on for $12 \mathrm{~h} / \mathrm{d}(\mathbf{O N} 12)$ in the other pen. Each pen received each treatment twice over the course of $4 \mathrm{~d}$. Feedline soakers were operated from 1200 to $0000 \mathrm{~h}$ for the ON12 treatment. Ambient temperature and relative humidity were measured at 15 -min intervals with 6 weather stations located throughout the farm. Weather stations were composed of a sensor (Hobo Pro H8, Onset Computer Corp.) and a solar radiation shield (M-RSA, Onset Computer Corp.).

\section{Statistical Analysis}

Core body temperature data were analyzed with a mixed model of SAS (version 9.1, SAS Institute Inc., Cary, NC), and significance was declared with a $P$-value $<0.05$. For the first experiment, pen, treatment, day within treatment, time of day, and treatment by time of day interaction were included as fixed effects. Cow within pen was assigned as the random effect. For the second experiment, time of day, treatment, and time by treatment were included as fixed effects, whereas cow within pen and day were assigned as random effects. Repeated measures over time were modeled with a variance component covariance structure, and denominator degrees of freedom were estimated using the KenwardRoger method.

\section{RESULTS AND DISCUSSION}

In experiment 1 , average ambient temperature was $30 \pm 0.9^{\circ} \mathrm{C}$, and average relative humidity was $44 \pm$ $14 \%$ (Figure 1). Cows with feedline soakers had a lower mean 24-h CBT $(P<0.001)$ than cows without feedline soakers $\left(38.80\right.$ vs. $\left.38.98 \pm 0.061^{\circ} \mathrm{C}\right)$. A significant treatment by time interaction $(P<0.001)$ was observed. The greatest treatment effects occurred at $2100 \mathrm{~h}$; treatment means at this time were 38.85 and $39.26 \pm$ $0.085^{\circ} \mathrm{C}$ for $\mathrm{ON} 24$ and OFF24 treatments, respectively (Figure 2).

In experiment 2 , average ambient temperature was $35 \pm 1.5^{\circ} \mathrm{C}$, and average relative humidity was $33 \pm$ $16 \%$ (Figure 3). Cows treated with feedline soakers for $12 \mathrm{~h}$ had a lower mean 24 -h CBT $(P<0.04)$ than 


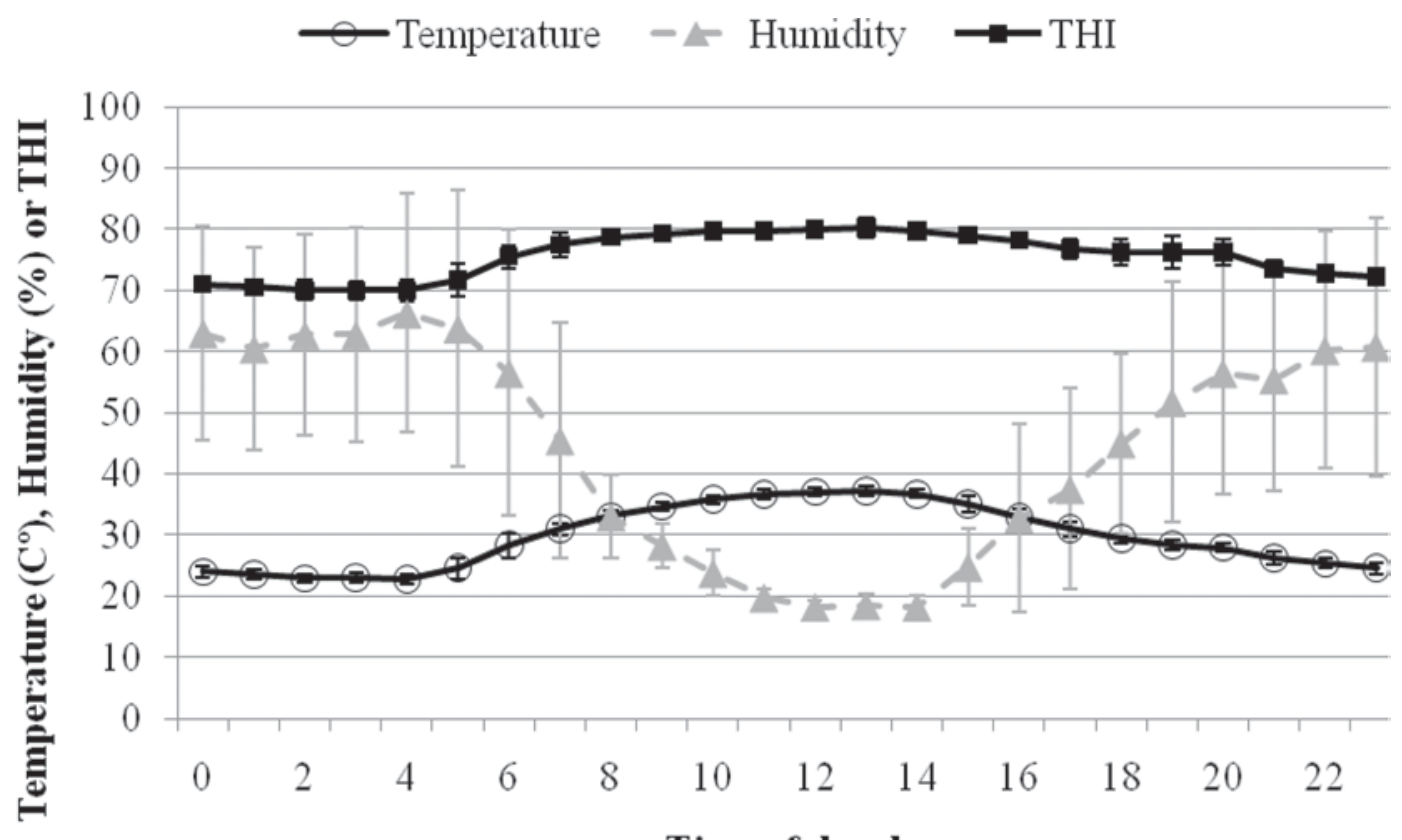

Time of day, h

Figure 1. Average ambient temperature, relative humidity, and temperature-humidity index (THI) \pm SD by hour (Exp. 1).

cows treated with KK systems alone (38.99 and 39.16 $\pm 0.084^{\circ} \mathrm{C}$, respectively). A significant treatment by time interaction $(P=0.02)$ was observed. The greatest treatment effects occurred at $1500 \mathrm{~h}$; treatment means at this time were 38.81 and $39.38 \pm 0.088^{\circ} \mathrm{C}$ for $\mathrm{ON} 12$ and OFF24 treatments, respectively (Figure 4).
Relocation of dairy farms because of population expansion and resource availability has led producers to overlook the climatic conditions where dairies are being built. In many cases, producers end up in arid regions where the climatic conditions exceed the thermoneutral zone (TNZ) for dairy cows $\left(20^{\circ} \mathrm{C}\right.$; NRC, 2001). In addi-

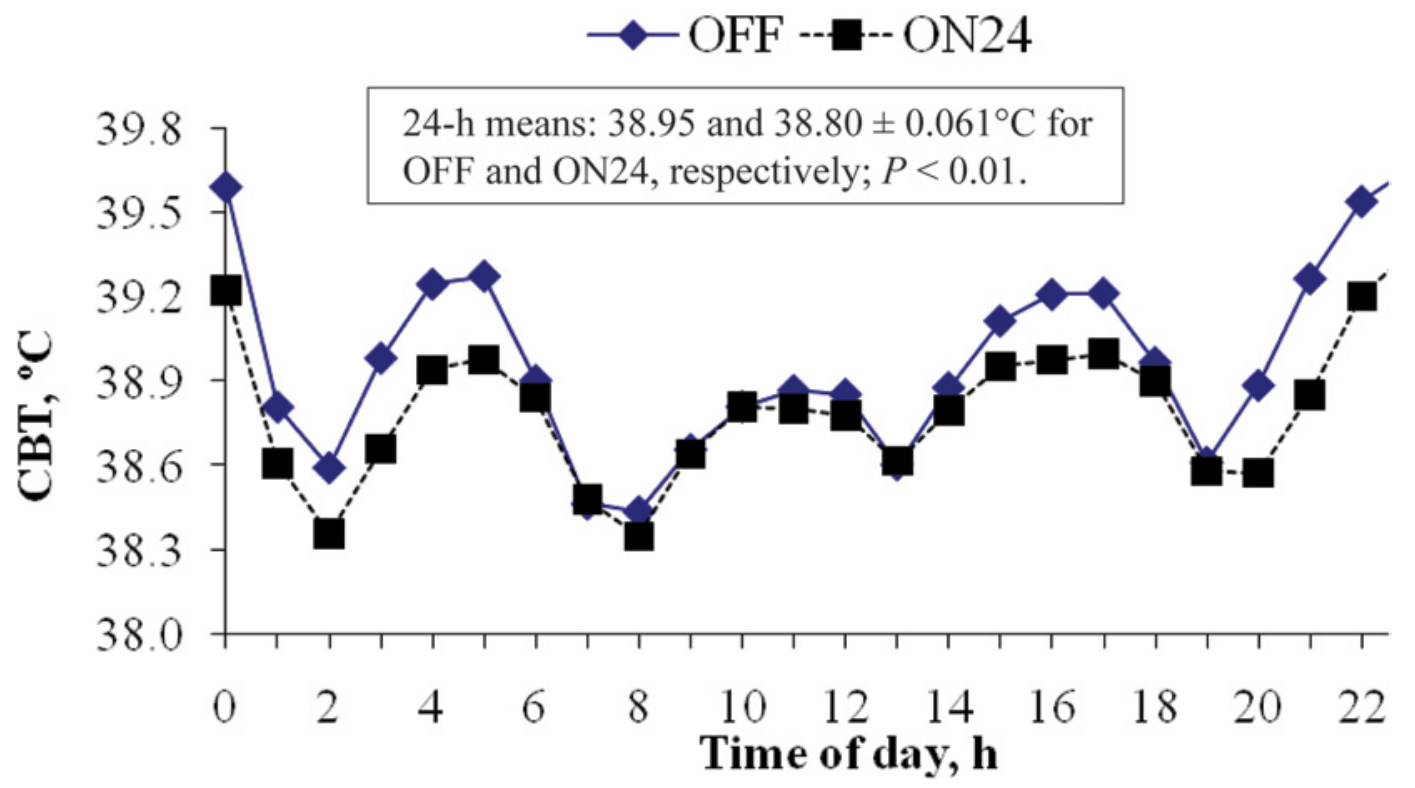

Figure 2. Core body temperature (CBT) of primiparous and multiparous cows $(\mathrm{n}=13)$ with the Korral Kool system (Korral Kool Inc., Mesa, AZ) operated for $24 \mathrm{~h} / \mathrm{d}$ with (ON24) or without (OFF) complementary feedline soakers run continuously (Exp. 1). Treatment by time interaction: $P<0.001 ; \mathrm{SEM}=0.085$. Color version available in the online PDF. 


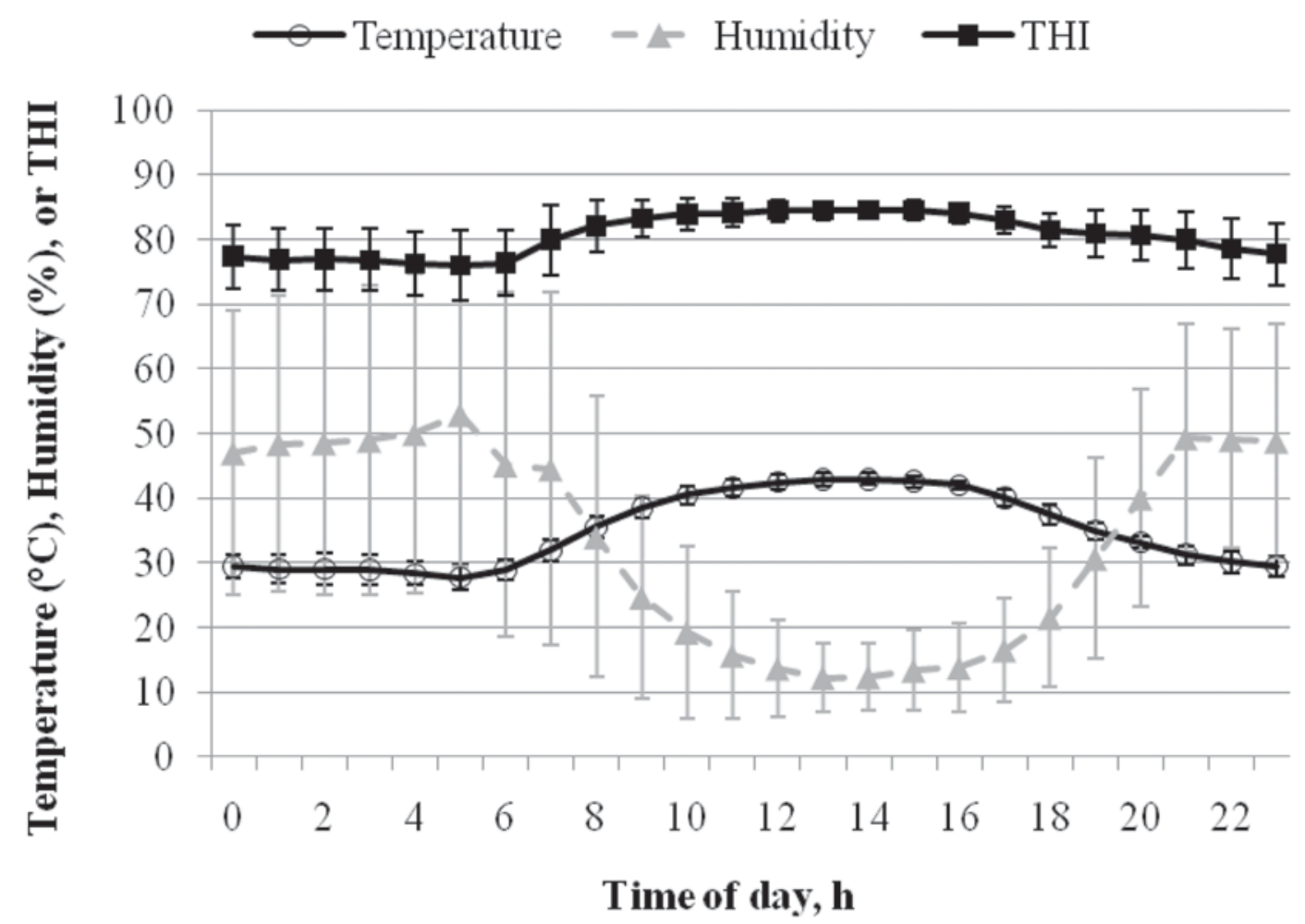

Figure 3. Average ambient temperature, relative humidity, and temperature-humidity index (THI) \pm SD by hour (Exp. 2).

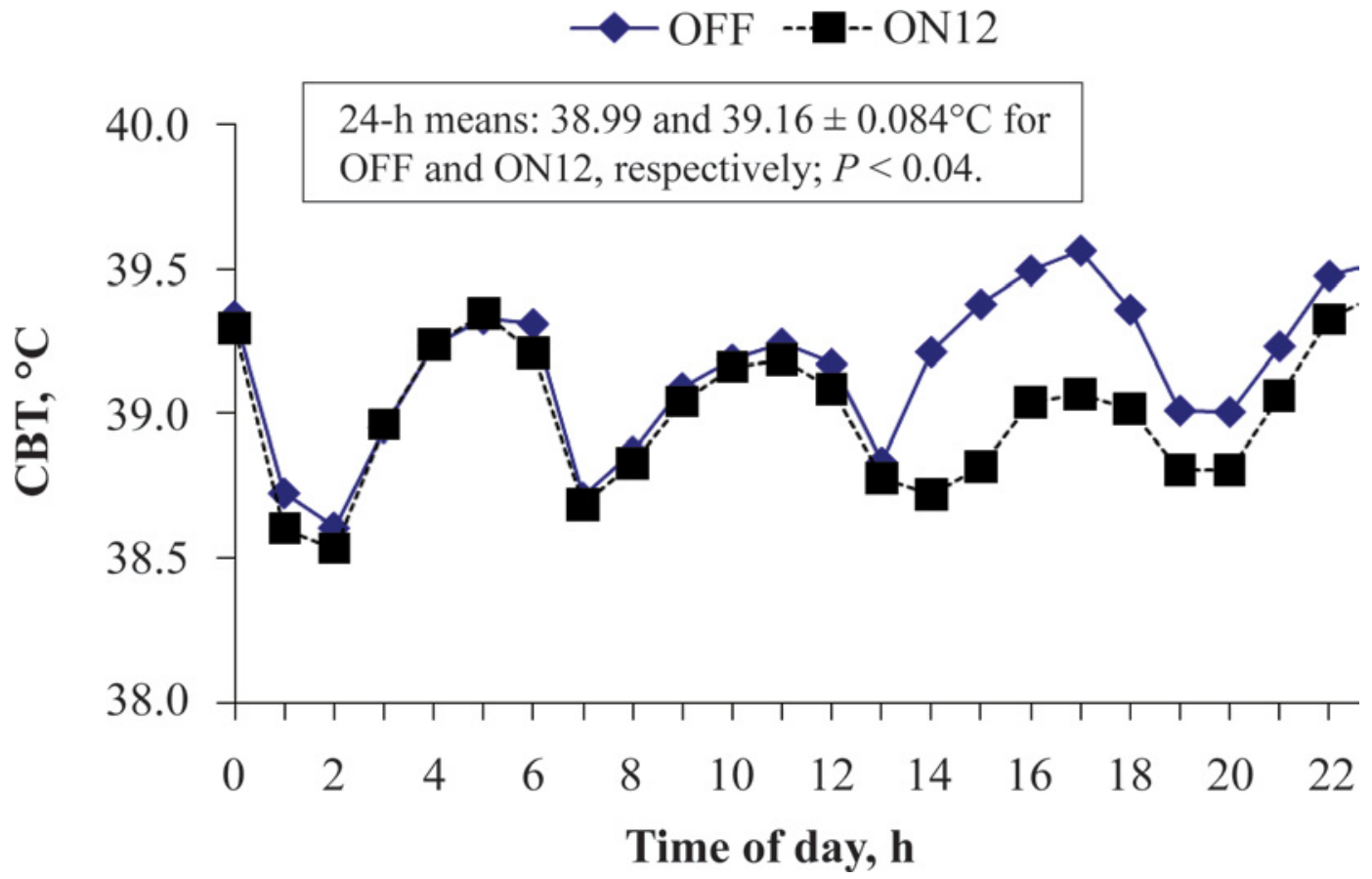

Figure 4. Core body temperature (CBT) of multiparous cows $(\mathrm{n}=20)$ with the Korral Kool system (Korral Kool Inc., Mesa, AZ) operated for $24 \mathrm{~h} / \mathrm{d}$ with $(\mathrm{ON} 12)$ or without (OFF) complementary feedline soakers run for $12 \mathrm{~h} / \mathrm{d}$ (Exp. 2). Treatment by time interaction: $P<0.02$; $\mathrm{SEM}=0.088$. Color version available in the online PDF. 
tion, when producers are unaware of the negative effect of heat stress on dairy cattle, cows are often improperly cooled, which compromises milk production, reproduction, and herd health.

The negative effects of heat stress on dairy cattle depend on the ambient temperature to which cows are exposed and the amount of time cows spend under ambient temperatures above their TNZ. As the temperature rises, losses in DMI and milk production increase (Rhoads et al., 2009). Reproduction is similarly compromised by elevated temperatures and long periods of ambient conditions (Hansen and Arechiga, 1999; Morton et al., 2007). Others have reported that animals are more susceptible to diseases and infections during summer months (Kadzere et al., 2002). Lameness increases during periods of heat stress as a result of behavioral changes (Cook et al., 2007) and also as a result of ruminal acidosis caused by both respiratory alkalosis (Benjamin, 1981) and loss of salivary buffers during panting/drooling.

Heat stress is the result of ambient conditions preventing cows from dissipating heat through the 4 routes of heat exchange (convection, radiation, conduction, and evaporation). As ambient temperature approaches CBT, evaporation becomes the primary route of heat exchange between the animal and the environment. When ambient temperatures exceed CBT, heat flow reverses and cows become heat sinks. Dukes (1947) reported that cows in thermoneutrality have a mean body temperature of $38.6^{\circ} \mathrm{C}$, but when climatic conditions exceed the upper limit of the comfort zone, a cow's CBT rises in a physiological response to heat stress.

Many cooling systems have been used to prevent heat stress in arid climates. However, only evaporative cooling has been shown to improve the environment of cows housed in these climatic conditions (Ryan et al., 1992; Correa-Calderon et al., 2004). Evaporative cooling decreases the air temperature surrounding the cow and increases the heat exchange between cows and the environment.

The KK evaporative cooling system is widely used in desert environments. Previous research showed that operating the KK system continuously decreased the CBT of primiparous and multiparous lactating Holstein dairy cows; however, the CBT of these cows still exceeded the mean CBT of cows under thermoneutral conditions (Ortiz et al., 2009). These results suggested that complementing the KK system with an additional cooling system might help cows dissipate more heat into the environment, counteracting the negative effects of heat stress during summer months.

Feedline soakers have been used to wet the skin of cows in the feeding area (Armstrong, 1994), and Schultz (1988) showed an increase in milk yield and reproduction of cows with feedline soakers. Each cycle in this system consists of a short phase of spraying water on the animals and a long phase during which the water absorbs heat and then evaporates. It takes approximately $2.43 \mathrm{~J}$ to evaporate $1 \mathrm{~mL}$ of water from the skin (Silanikove, 2000). Previous studies showed that wetting the skin of Holstein cows increased the evaporation rate from $68 \pm 8$ to $508 \pm 114 \mathrm{~g} / \mathrm{m}^{2}$ per hour (Gebremedhin et al., 2008).

The frequency of each cycle has a great effect on the efficiency of heat abatement. Brouk et al. (2003) reported that feedline soakers set at 5-min cycles were more efficient at decreasing skin temperatures, respiration rates, and CBT of cows than feedline soakers set at 10- or 15-min cycles.

High ambient temperatures were observed during the present experiments. The CBT of cows significantly decreased when feedline soakers complemented the KK system for 12 and $24 \mathrm{~h}$. Additionally, the greatest difference in the CBT was observed during peak periods of heat stress. Thus, complementing the KK systems with feedline soakers maintained a more constant CBT and may prevent physiological changes due to elevated CBT.

Even though complementing the KK system with feedline soakers decreased the CBT of lactating dairy cows, the mean CBT of these cows still exceeded that of cows in the TNZ. Using fans on the feedline with soakers may help reduce CBT. Brouk et al. (2003) showed that fans and soakers caused a greater decrease in CBT, skin temperature, and respiration rates of 16 lactating dairy cows compared with using fans or soakers alone. Future research is needed to investigate the effect of supplementing the KK system with feedline soakers and fans on cows housed in desert environments.

\section{CONCLUSIONS}

In conclusion, the results of these experiments showed that complementing the KK system with feedline soakers for at least $12 \mathrm{~h} / \mathrm{d}$ during peak periods of heat stress could decrease the CBT of lactating dairy cows in desert environments. However, the combined systems were not adequate to lower CBT to normal temperatures in this extreme environment.

\section{ACKNOWLEDGMENTS}

The authors express their appreciation to NADA AlOthman (Al Ahsa, Saudi Arabia) for their support in development of these experiments.

\section{REFERENCES}

Armstrong, D. V. 1994. Heat stress interaction with shade and cooling. J. Dairy Sci. 77:2044-2050. 
Armstrong, D. V., M. J. VanBaale, S. Rungruang, V. Wuthironarith, M. J. Brouk, and J. F. Smith. 2007. Effect of soaking dairy cows at the feed line on animal body temperature in a tunnel ventilated barn equipped with evaporative pads located in a tropical climate, Thailand. J. Dairy Sci. 90(Suppl. 1):239. (Abstr.)

Benjamin, M. M. 1981. Fluid and electrolytes. Page 213 in Outline of Veterinary Clinical Pathology. Iowa State Univ. Press, Ames.

Brouk, M. J. 2005. Evaluating and selecting cooling systems for different climates. Pages 33-40 in Proc. Western Dairy Management Conference. Kansas State Univ., Manhattan.

Brouk, M. J., J. F. Smith, and J. P. Harner III. 2003. Effect of sprinkling frequency and airflow on respiration rate, body surface temperature and body temperature of heat stressed dairy cattle. Pages 263-268 in Proc. Fifth International Dairy Housing. Kansas State Univ., Manhattan.

Cook, N. B., R. L. Mentink, T. B. Bennett, and K. Burgi. 2007. The effect of heat stress and lameness on time budgets of lactating dairy cows. J. Dairy Sci. 90:1674-1682.

Correa-Calderon, A., D. Armstrong, D. Ray, S. DeNise, M. Enns, and C. Howison. 2004. Thermoregulatory responses of Holstein and Brown Swiss heat-stressed dairy cows to two different cooling systems. Int. J. Biometeorol. 48:142-148.

Dukes, H. H. 1947. The Physiology of Domestic Animals. 6th ed. Comstock Publishing Company Inc., Ithaca, NY.

Gebremedhin, K. G., P. E. Hillman, C. N. Lee, R. J. Collier, S. T. Willard, J. Arthington, and T. M. Brown-Brandl. 2008. Sweating rates of dairy and feedlot cows under stressful thermal environments. ASABE paper No. 701P0408 in Proceedings of the Livestock Environment VIII Conference, Iguassu Falls, Brazil.

Hansen, P. J., and C. F. Arechiga. 1999. Strategies for managing reproduction in the heat-stressed dairy cow. J. Anim. Sci. 77(ESuppl. 2):E36-E50.
Kadzere, C. T., M. R. Murphy, N. Silanikove, and E. Maltz. 2002. Heat stress in lactating dairy cows: A review. Livest. Prod. Sci. 77:59-91.

Maia, A. S. C., R. G. daSilva, and C. M. Battiston Loureiro. 2005. Sensible and latent heat loss from the body surface of Holstein cows in a tropical environment. Int. J. Biometeorol. 50:17-22.

Morton, J. M., W. P. Tranter, D. G. Mayer, and N. N. Jonsson. 2007. Effects of environmental heat on conception rates in lactating dairy cows: Critical periods of exposure. J. Dairy Sci. 90:2271-2278.

NRC. 2001. Nutrient Requirements of Dairy Cattle. 7th ed. Natl. Acad. Sci., Washington, DC.

Ortiz, X. A., J. F. Smith, B. J. Bradford, J. P. Harner III, and A. Oddy. 2009. Effects of Korral Kool running time on core body temperature of dairy cows in a desert environment. J. Dairy Sci. 92(Suppl. 1):2356-2357. (Abstr.)

Rhoads, M. L., R. P. Rhoads, M. J. VanBaale, R. J. Collier, S. R. Sanders, W. J. Weber, B. A. Crooker, and L. H. Baumgard. 2009. Effects of heat stress and plane of nutrition on lactating Holstein cows: I. Production, metabolism, and aspects of circulating somatotropin. J. Dairy Sci. 92:1986-1997.

Ryan, D. P., M. P. Boland, E. Kopel, D. Armstrong, L. Munyakazi, R. A. Godke, and R. H. Ingraham. 1992. Evaluating two different evaporative cooling management systems for dairy cows in a hot, dry climate. J. Dairy Sci. 75:1052-1059.

Schultz, T. A. 1988. California dairy corral manger mister installation. Paper No. 88-4056, Am. Soc. Agric. Eng., St. Joseph, MI.

Silanikove, N. 2000. Effects of heat stress on the welfare of extensively managed domestic ruminants. Livest. Prod. Sci. 67:1-18.

St-Pierre, N. R., B. Cobanov, and G. Schnitkey. 2003. Economic losses from heat stress by us livestock industries. J. Dairy Sci. 86(E Suppl.):E52-E77. 